\title{
Ultrasonography in the evaluation of bone erosions
}

\author{
W Grassi, E Filippucci, A Farina, F Salaffi, C Cervini
}

\begin{abstract}
Objective-To demonstrate the diagnostic efficacy of ultrasonography in depicting erosions in patients with rheumatoid arthritis and to compare sonographic and radiographic findings.

Methods-Sonographic images were obtained with an AU-4 Idea Esaote Biomedica (Genoa, Italy) equipped with a 13 MHz linear transducer.

Results-The images reported in this essay are representative examples of the ability of ultrasonography to detect and characterise even minimal bone margin changes in rheumatoid arthritis.

Conclusion-Ultrasonography with very high frequency transducers can depict bone erosions in early target areas of bone resorption. However, further studies are needed to validate this technique and to evaluate the relation between sonographic findings and those obtained with other imaging techniques (standard radiology, magnetic resonance). (Ann Rheum Dis 2001;60:98-103)
\end{abstract}

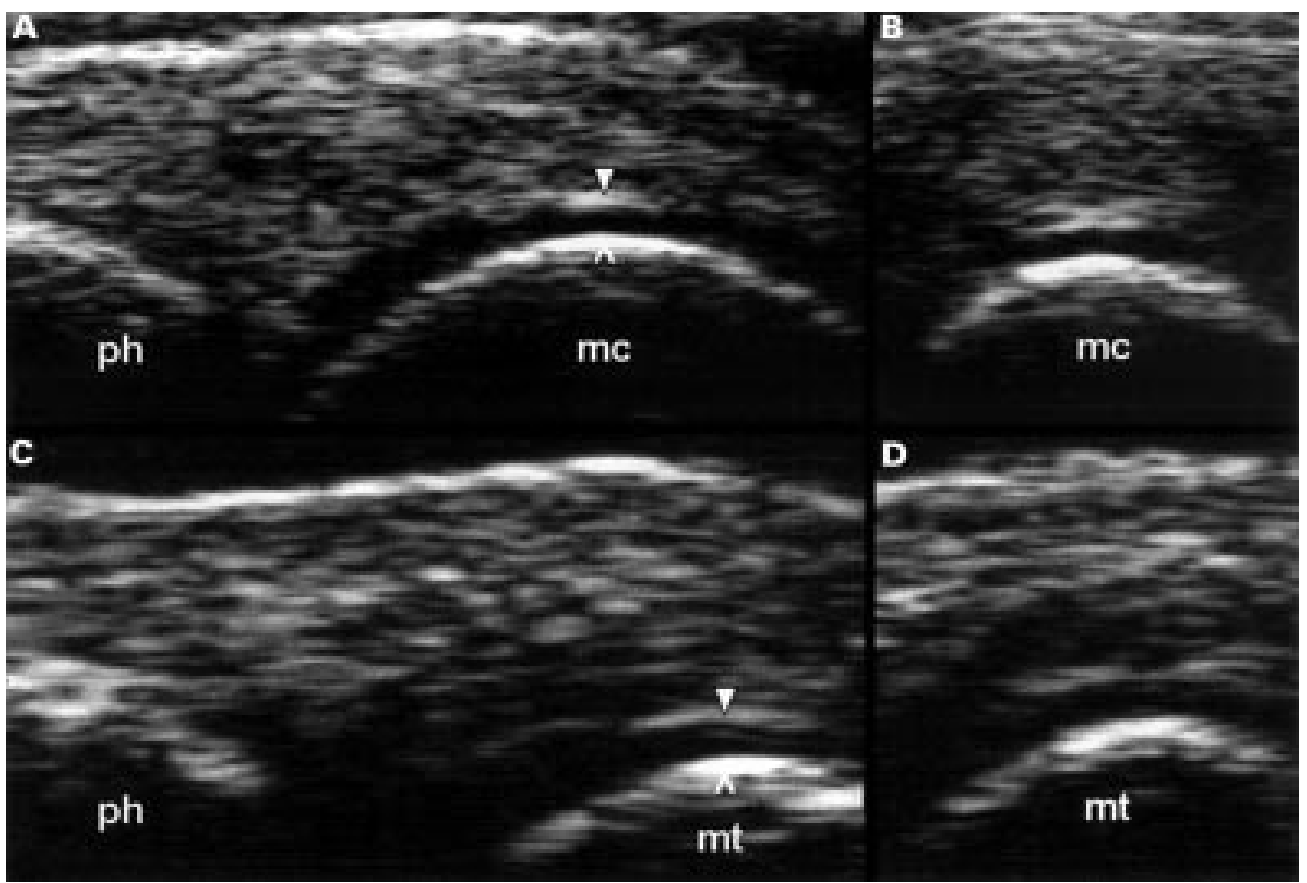

Figure 1 Healthy subject. Metacarpophalangeal joint of the second finger: longitudinal $(A)$ and transverse (B) dorsal scans. Metatarsophalangeal joint of the fifth toe: longitudinal (C) and transverse (D) dorsal scans. Articular cartilage appears as a clearly defined anechoic band delimited by sharp hyperechoic borders corresponding to the bone margin (arrowhead) and to the cartilage soft tissue interface (white triangle). $m c=$ metacarpal head; $m t=$ metatarsal head; $p h=$ phalanx.
Ultrasonography is a highly sensitive tool for the identification of fine soft tissue changes. It is increasingly used in rheumatological practice, especially to assess tendon and joint involvement. ${ }^{1-6}$ Based on the high resolution performance of the last generation linear transducers, it can be suggested that ultrasonography might also be used as an adjunctive imaging tool in early detection of bone erosions in patients with recent onset rheumatoid arthritis (RA). Initial reports suggested that ultrasonography appears to be a promising technique for detecting bone erosions. ${ }^{7-11}$ The aims of this pictorial essay were to demonstrate the diagnostic efficacy of ultrasonography in depicting erosions in patients with RA and to compare sonographic and radiographic findings of the early target of the erosive process in RA.

\section{Methods}

Sonographic images were obtained with an AU-4 Idea Esaote Biomedica (Genoa, Italy) equipped with a $13 \mathrm{MHz}$ linear transducer.

The sonograms of this study were taken in six representative patients with RA, fulfilling
Department of Rheumatology, University of Ancona, Italy

W Grassi

E Filippucci

A Farina

F Salaffi

C Cervini

Correspondence to: Professor W Grassi, Clinica Reumatologica, Universit degli Studi di Ancona, Ospedale "A Murri", Via dei Italy

reuman@popcsi.unian.it

Accepted 16 August 2000 


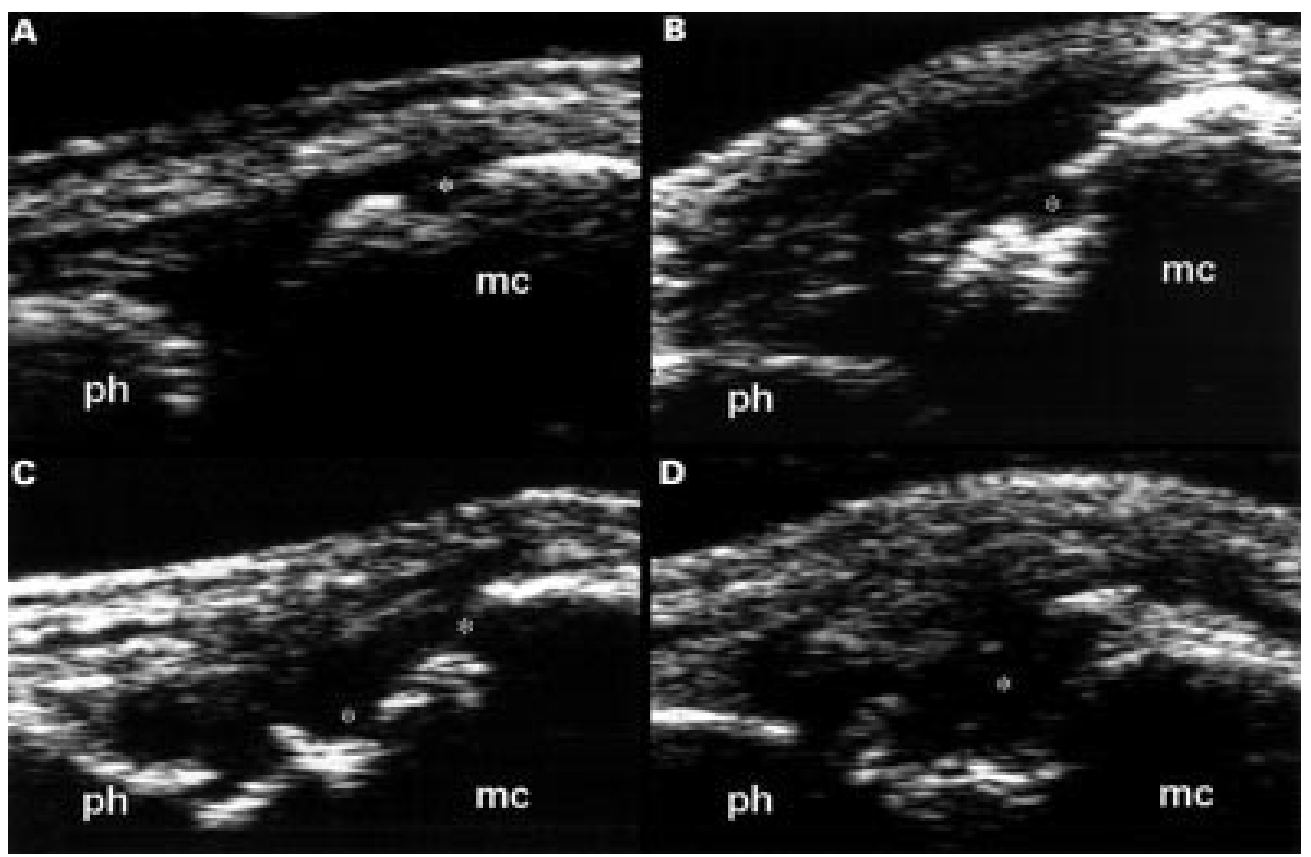

Figure 2 Rheumatoid arthritis. Longitudinal dorsal scans. Sonographic features of bone erosions of the metacarpal head. $(A$ and $B)$ Early disease. $(C$ and $D)$ Late disease. ${ }^{*}=$ erosion; $m c=$ metacarpal head; $p h=$ phalanx.

the American College of Rheumatology (formerly, the American Rheumatism Association) criteria, and three healthy subjects who had no history or signs of hand disease. ${ }^{12}$ Sonographic assessment was performed at the second metacarpophalangeal (MCP) joint and the fifth metatarsophalangeal (MTP) joint, which are among the anatomical areas affected earliest in the erosive process. ${ }^{13} 14$ All joints were studied by the following standard scans: longitudinal dorsal scan, longitudinal lateral scan, longitudinal volar scan, transverse dorsal scan, transverse lateral scan, and transverse volar scan.
Moreover, both on longitudinal and transverse scans, the probe was moved over the joint to allow a careful assessment of the examined area (multiplanar dynamic assessment). Multiplanar sonographic scans were compared with standard $x$ ray pictures of the selected areas.

\section{Results}

Figure 1 shows the standard sonographic appearance of the second MCP joint and of the fifth MTP joint, obtained with a $13 \mathrm{MHz}$ linear transducer on the main scanning planes (dorsal longitudinal and transverse views).

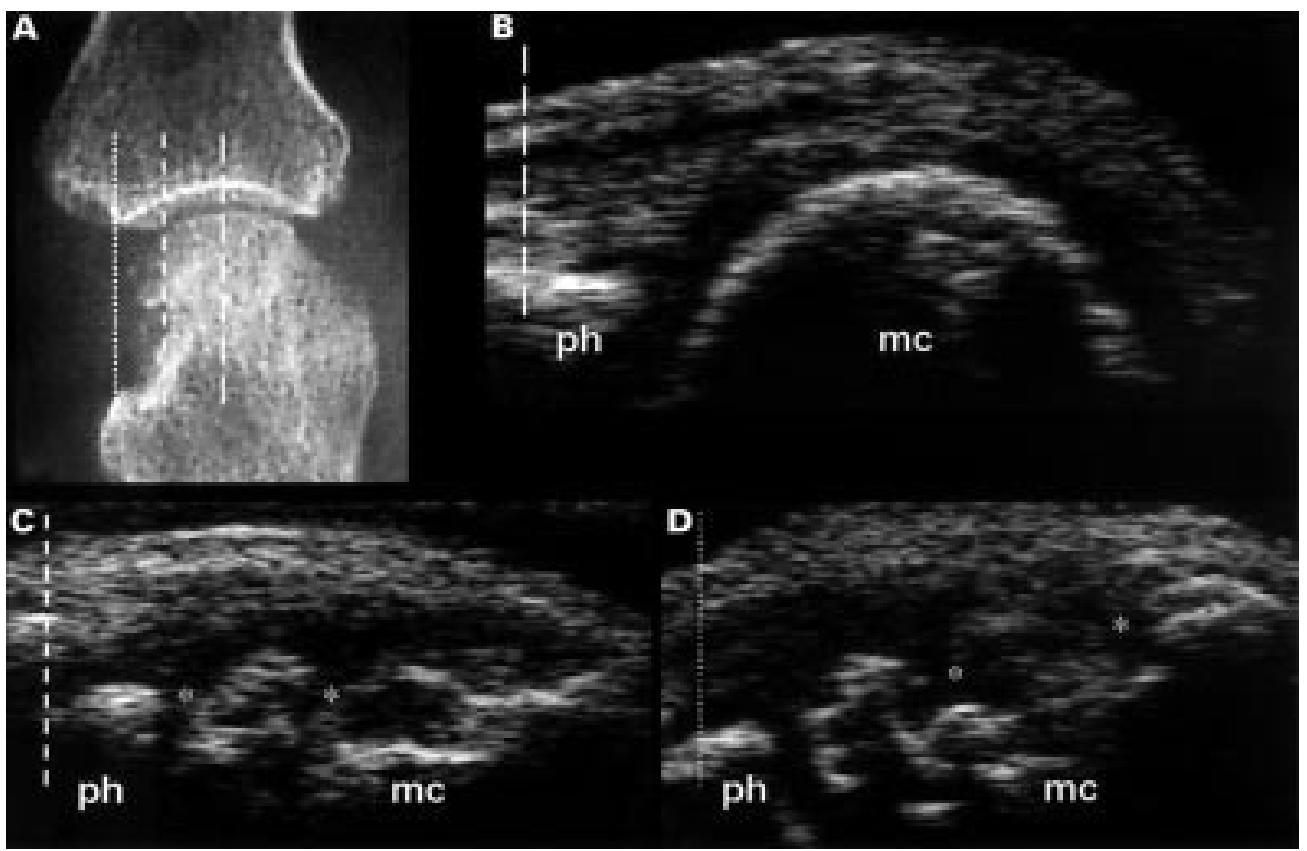

Figure 3 Rheumatoid arthritis. Longitudinal dorsal views at different scanning planes as indicated on the corresponding standard radiogram (A). (B) Longitudinal dorsal scan shows a still well defined bone margin of the metacarpal head. (C) Longitudinal dorsal scan on a contiguous plane shows a clearly evident erosion ( $\left.{ }^{\star}\right)$. (D) Radial scan of the joint showing a large area of bone resorption $(*)$. mc $=$ metacarpal head; $p h=$ phalanx. 


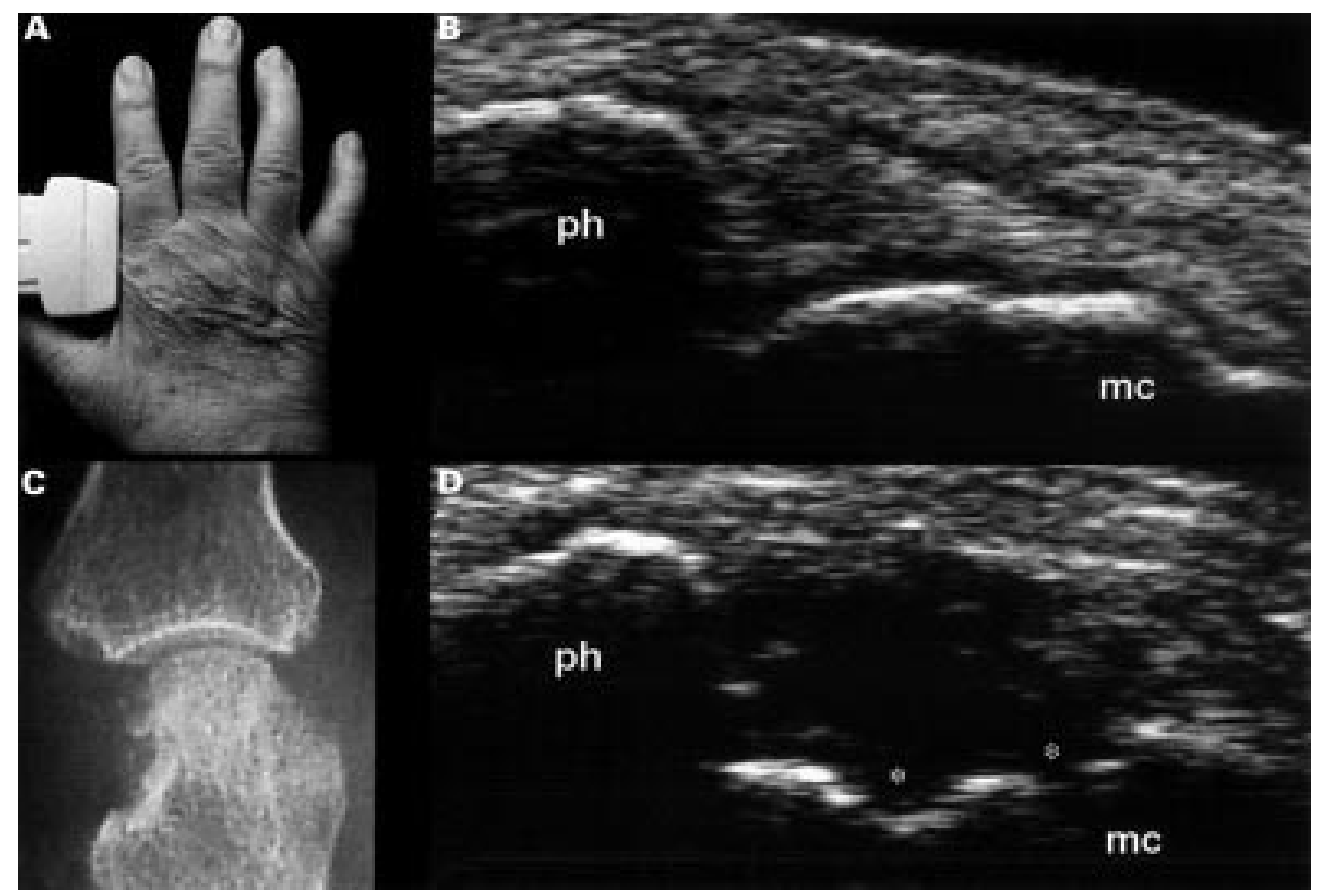

Figure 4 Rheumatoid arthritis. Metacarpophalangeal joint of the second finger (same patient as fig 3). (A) Coronal scan. (B) Healthy subject. The coronal view demonstrates the good correspondence between radiographic $(C)$ and sonographic (D) changes of the bone margin. ${ }^{\star}=$ erosion; $m c=$ metacarpal head; $p h=$ phalanx.

The second MCP joint was also explored on a longitudinal dorsal scan with the finger in maximal active flexion. The bone margin is clearly detectable in healthy subjects as a sharp, homogeneous, and hyperechoic band with a posterior acoustic shadow. Bone erosion appears as an interruption of the bone margin (fig 2).

Multiplanar capabilities of ultrasonography allow a careful assessment of the bone surfaces on more views than those allowed by standard $x$ ray. This improves the sensitivity of the ultrasonography in detecting small erosions in areas unexplored by standard views. Figure 3 shows the diagnostic efficacy of multiplanar sonographic assessment of the second MCP joint. The radial view (fig 4) is very useful in depicting bone changes of the metacarpal head, which is a typical early target of the erosive process in RA.

The fifth MTP joint is another key target of early RA. Initial erosions of the fifth MTP

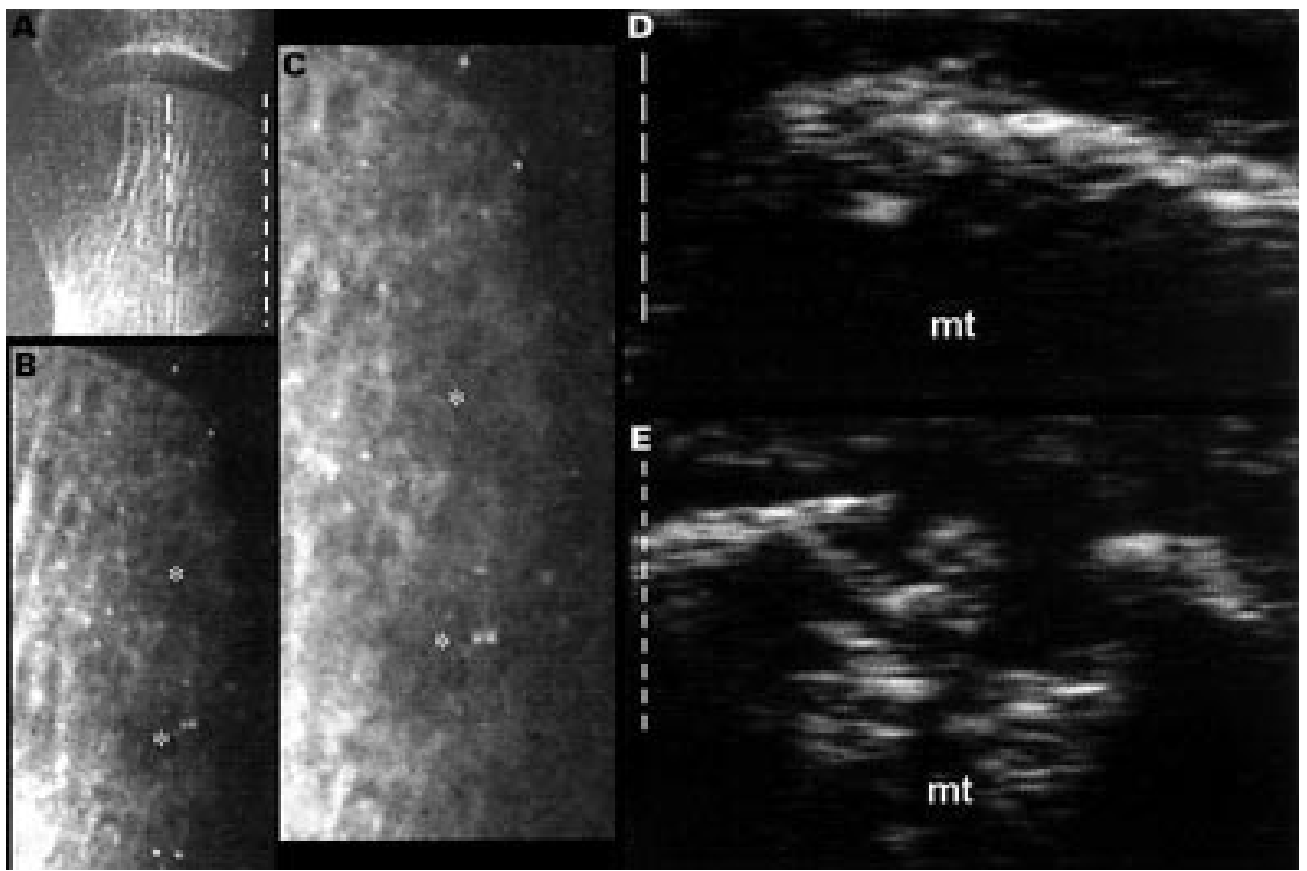

Figure 5 Rheumatoid arthritis. Metatarsal head of the fifth toe. Standard $x$ ray $(A)$ does not reveal clearly evident erosive changes (Sharp's score $=1)$. ( $B$ and $C$ ) Off line digitalised radiograms show two areas of lower bone density (*) and loss of the normal sharp bone margin of the metatarsal head. (D) Longitudinal dorsal scan of metatarsal head does not reveal bone margin changes. (E) Coronal scan discloses clearly evident erosions of the metatarsal head, probably corresponding to the areas of low bone density on $x$ ray. $m t=$ metatarsal head. 


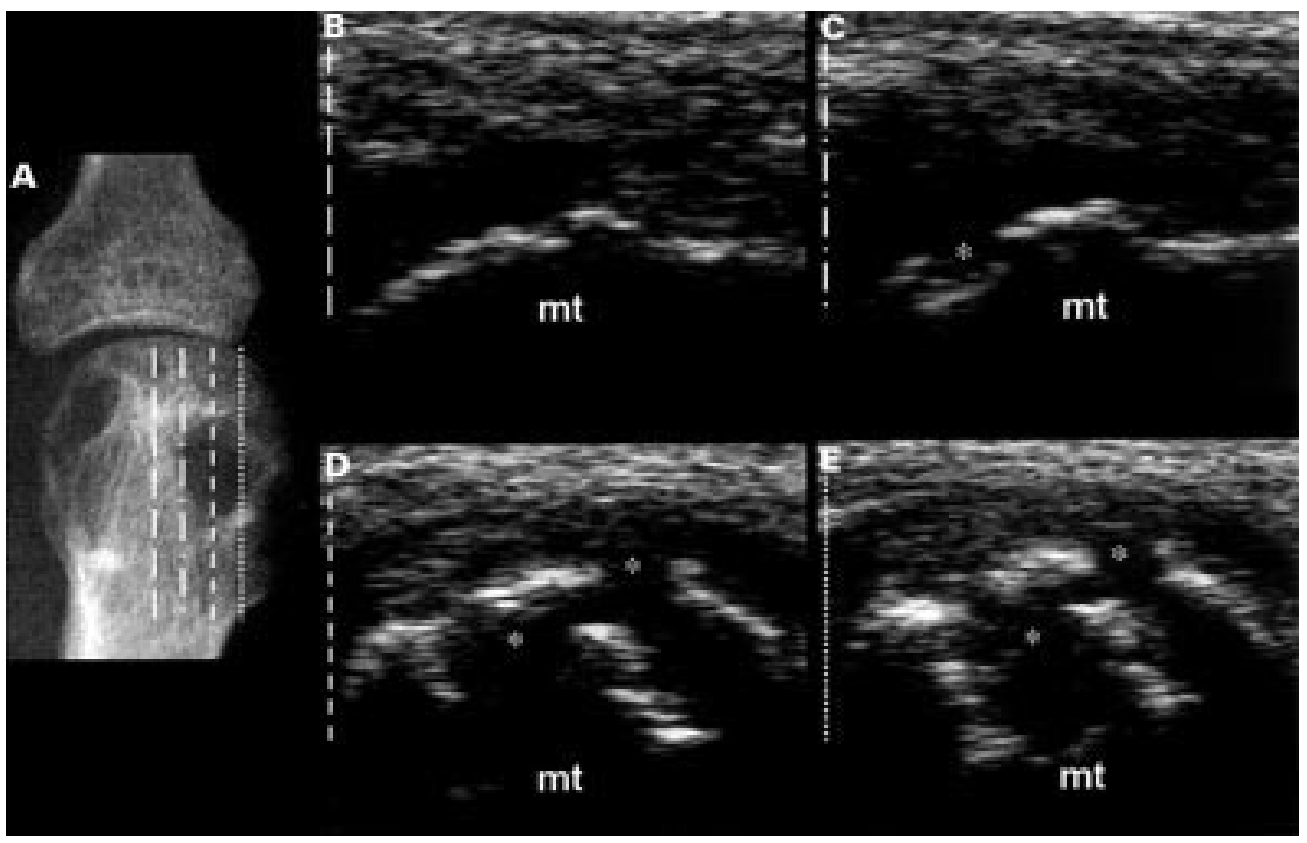

Figure 6 Rheumatoid arthritis. Metatarsophalangeal joint of the fifth toe. Sonographic features of the metatarsal head at different scanning planes. These pictures demonstrate the potential role of multiplanar sonographic examination in detecting bone erosion $\left(^{\star}\right) . m t=$ metatarsal head.

joints are among the earliest indicators of an erosive process but they can be frequently missed especially in patients with low quality radiographic documentation. Figure 5 shows a typical example of an $x$ ray of the fifth MTP joint of uncertain interpretation (a Sharp's score of 1 is probably the most appropriate). Sonographic examination does not show any features indicating an erosive process on the standard longitudinal dorsal view. Conversely, lateral scan shows an interruption of the cortex of the metatarsal head with two clearly evident erosions. A reassessment of the $x$ ray performed after an off line digitalisation of the standard radiogram and a subsequent image enhancement and analysis showed that two areas of low bone density could correspond to the erosions depicted by ultrasonography on a coronal plane (fig 5).

Figure 6 shows the different sonographic views that can be obtained by examining the fifth MTP joint on different planes. Figure 7 is a representative example of the sonographic appearance of severe erosive changes. In

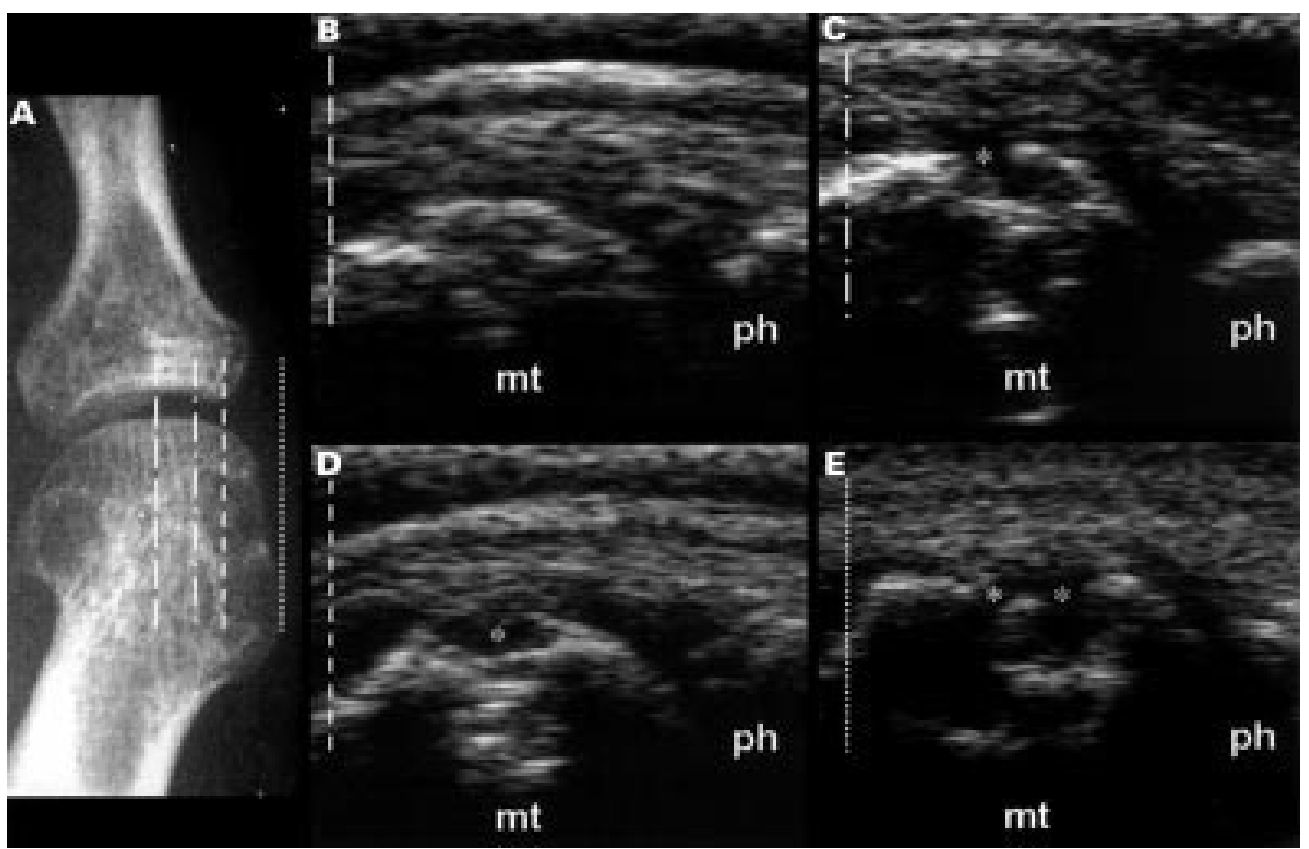

Figure 7 Rheumatoid arthritis. Metatarsophalangeal joint of the fifth toe. Sonographic findings in late rheumatoid arthritis with cystic like areas of bone resorption on posteroanterior view. (A) Standard x ray. (B) Longitudinal dorsal scan between the two areas of bone erosions does not show any interruption of bone margin. (C) Sonographic scan on the border of the erosion. (D) Longitudinal scan in the centre of the area of bone resorption. (E) Coronal scan. ${ }^{*}=$ erosion; $m t$ $=$ metatarsal head; $p h=$ phalanx. 


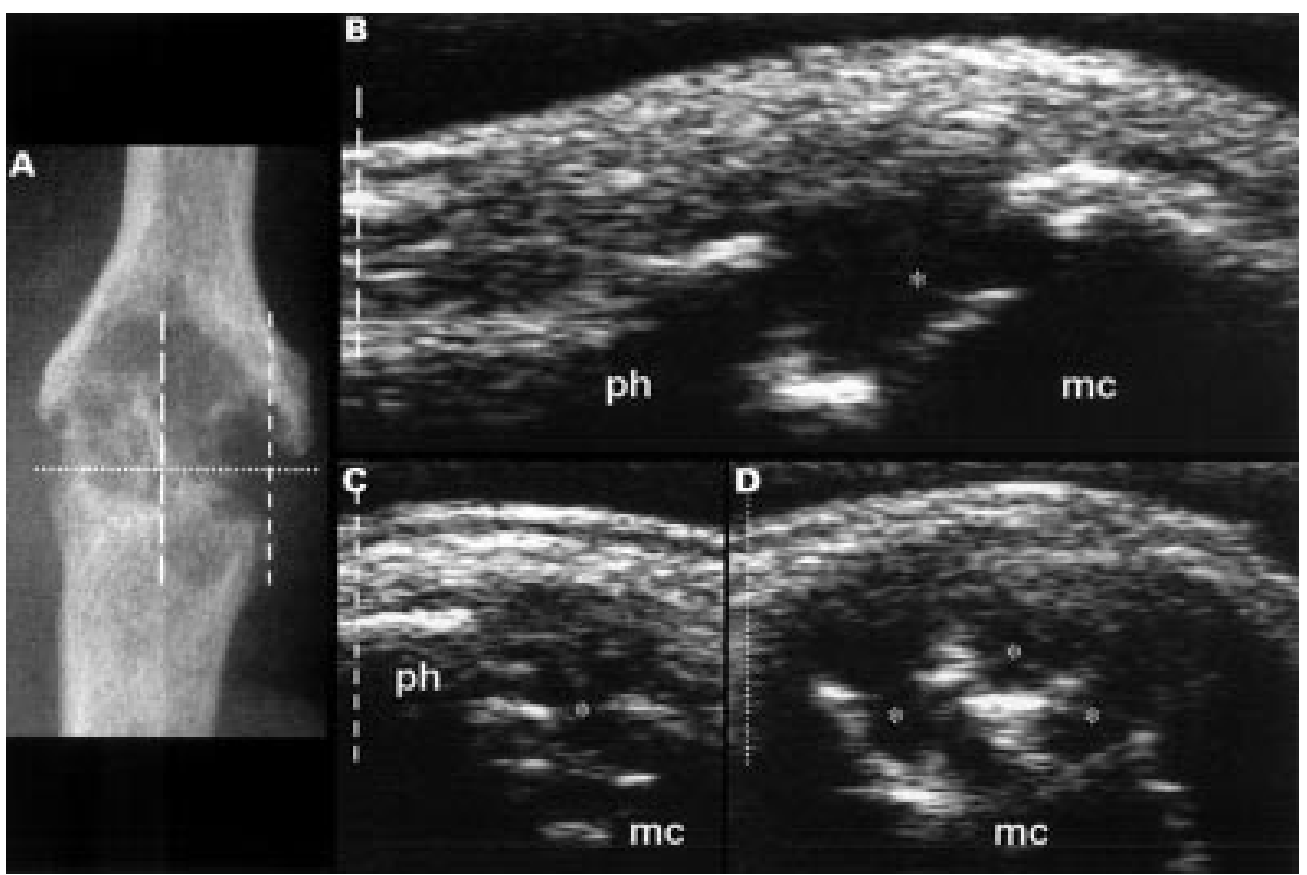

Figure 8 Rheumatoid arthritis. Metacarpophalangeal joint of the second finger. (A) Standard x ray. Multiplanar examination in patient with late disease. Ultrasonography is able to depict the extent of bone resorption both on longitudinal $(B$ and $C)$ and transverse scans $(D) . m c=$ metacarpal head; $p h=$ phalanx; ${ }^{\star}=$ erosion.

patients with advanced joint damage, ultrasonography clearly depicts areas of extensive bone resorption (fig 8). The extension of the erosive changes can be documented both on longitudinal and transverse scans.

\section{Discussion}

Multiple imaging modalities are currently available to explore bone and soft tissue involvement in RA. ${ }^{75}$ Standard radiology is still the best method for detecting and monitoring erosive changes. ${ }^{16-18}$ Early depiction of erosions by ultrasonography may have a useful role in assessing the course of the anatomical damage in patients with RA. ${ }^{19}$

This pictorial essay aimed at demonstrating that ultrasonography with very high frequency transducers can depict bone erosions, especially in the early target areas of bone resorption (second MCP and fifth MTP joints). ${ }^{20-24}$ These joints can be carefully explored because of the multiplanar capability of ultrasonography.

Our preliminary investigation of a representative group of patients with RA shows that last generation ultrasonography equipment allows a safe, quick, inexpensive, and accurate identification of small bone erosions.

Despite the lack of standardised criteria for sonographic assessment of bone erosions in RA, our pictorial essay provides a convincing evidence of the capabilities of ultrasonography in clearly depicting small erosions, even when they appear as a vanishing aspect of the cortical plate on standard $x$ ray. Because the appearance of bone erosions on radiographs of a patient with a recent onset arthritis indicates a poor prognosis, the possibility of demonstrating small hidden erosions at the level of the early targets of the disease opens up interesting perspectives of research. Further studies are needed to validate this technique and to evaluate the relation between sonographic findings and those obtained with other imaging techniques (standard radiology, magnetic resonance).

Supported by Università degli Studi di Ancona grant Ref. n.601 17-03-1999.

1 Grassi W, Cervini C. Ultrasonography in rheumatology: an evolving technique. Ann Rheum Dis 1998;57:268-71.

2 Wakefield RJ, Gibbon WW, Emery P. The current status of ultrasonography in rheumatology. Rheumatology 1999;38: 195-201.

3 Gibbon WW, Wakefield RJ. Ultrasound in inflammatory disease. Radiol Clin North Am 1999;37:633-51.

4 Martinoli C, Bianchi S, Derchi LE. Tendon and nerve sonography. Radiol Clin North Am 1999;37:691-711.

5 Grassi W, Tittarelli E, Blasetti P, Pirani O, Cervini C. Finger tendon involvement in rheumatoid arthritis: evaluation with high-frequency sonography. Arthritis Rheum 1995; with high-fred

6 Erickson SJ. High-resolution imaging of the musculoskeletal system. Radiology 1997;205:593-618.

7 Backhaus M, Kamradt T, Sandrock D, Loreck D, Fritz J, Wolf KJ, et al. Arthritis of the finger joints: a comprehensive approach comparing conventional radiography, scintigraphy, ultrasound, and contrast-enhanced magnetic resonance imaging. Arthritis Rheum 1999;42:1232-45.

8 Grassi W, Tittarelli E, Pirani O, Avaltroni D, Cervini C. Ultrasound examination of metacarpophalangeal joints in rheumatoid arthritis. Scand J Rheumatol 1993;22:243-7.

9 McGonagle D, Gibbon W, O'Connor P, Blythe D, Wakefield $\mathrm{R}$, Green $\mathrm{M}$, et al. A preliminary study of bone erosion in $\mathrm{R}$, Green $\mathrm{M}$, et al. A preliminary study of bone erosion in

10 early rheumatoid arthritis. Rheumatology 1999;38:329-31. ultrasound: a superior method to radiography for detecting ultrasound: a superior method to radiography for detecting
cortical bone erosions in rheumatoid arthritis [abstract]. Br

11 Wakefield RJ, McGonagle D, Green MJ, Proudman S, Pease $\mathrm{C}$, Veale $\mathrm{D}$, et al. A comparison of high resolution sonography with MRI and conventional radiography for the detection of erosions in early rheumatoid arthritis [abstract]. Arthritis Rheum 1997;40:S511.

12 Arnett FC, Edworthy SM, Bloch DA, McShane DJ, Fries $\mathrm{JF}$, Cooper NS, et al. The American Rheumatism Association 1987 revised criteria for the classification of rheumatoid arthritis. Arthritis Rheum 1988;31:315-24.

13 Brower AC. Rheumatoid arthritis and spondyloarthropathy. Imaging. In: Klippel JH, Dieppe PA, ed. Rheumatology. London: Mosby, 1998:5.5.1-8.

14 Sharp JT. An overview of radiographic analysis of joint damage in rheumatoid arthritis and its use in metaanalysis. J Rheumatol 2000;27:254-60.

15 Hau M, Schultz H, Tony HP, Keberle M, Jahns R, Haerten $\mathrm{R}$, et al. Evaluation of pannus and vascularization of the metacarpophalangeal and proximal interphalangeal joints 
in rheumatoid arthritis by high-resolution ultrasound (multidimensional linear array). Arthritis Rheum 1999;42: 2303-8.

16 Graudal NA, Jurik AG, de Carvalho A, Graudal HK. Radiographic progression in rheumatoid arthritis: a long-term prospective study of 109 patients. Arthritis Rheum 1998;41:1470-80.

17 Ferraccioli GF. Radiographic assessment of rheumatoid arthritis. Controversies and perspectives. Clin Exp Rheumatol 1990;8:529-30.

18 Turner RA, Flint KP, Semble EL, Agudelo CA. Clinical evaluation of radiographic progression in rheumatoid arthritis. Clin Exp Rheumatol 1990;8:583-6.

19 Salaffi F, Ferraccioli G, Peroni M, Carotti M, Bartoli E, Cervini C. Progression of erosion and joint space narrowing scores in rheumatoid arthritis assessed by nonlinear models. J Rheumatol 1994;21:1626-30.

20 Halla JT, Fallahi S, Hardin JG. Small joint involvement: a systematic roentgenographic study in rheumatoid arthritis. Ann Rheum Dis 1986;45:327-30.

21 Sharp JT, Bluhm GB, Brook A, Brower AC, Corbett M, Decker JL, et al. Reproducibility of multiple-observer scoring of radiologic abnormalities in the hand and wrist of patients with rheumatoid arthritis. Arthritis Rheum 1985; 28:16-24.

22 Sharp JT, Young DY, Bluhm GB, Brook A, Brower AC, Corbett $M$, et al. How many joints in the hands and wrists should be included in a score of radiologic abnormalities used to assess rheumatoid arthritis? Arthritis Rheum 1995; 28:1326-35.

23 Plant MJ, Jones PW, Saklatvala J, Ollier WER, Dawes PT. Patterns of radiological progression in early rheumatoid 8 year prospective study. J Rheumatol 1998;25:417-26.

24 Rau R, Wassenberg S, Herborn G, Stucki G, Gebler A. A new method of scoring radiographic change in rheumatoid new method of scoring radiographic change
arthritis. J Rheumatol 1998;25:2094-107. 